\title{
P-DELTA ACTIONS IN SEISMIC RESISTANT STRUCTURES
}

\author{
R. C. Fenwick1, B. J. Davidson'2 and B. T. Chung ${ }^{3}$
}

\begin{abstract}
SYNOPSIS
The results of several thousands of inelastic time history analyses, which have been made on single degree of freedom structures to assess P-delta effects induced in earthquakes, are reviewed. The principal factors influencing P-delta actions are shown to be the ductility, the duration of the severe ground motion, the level of damping and the period of the structure. A method of designing for P-delta effects for single degree of freedom structures is presented. A limited number of analyses of multistorey frames and walls indicate that the approach may be used for multi-storey structures. This paper gives background information on the P-delta method of analysis given in an appendix to the commentary of the proposed loading code ${ }^{1}$.
\end{abstract}

\section{Basic Mechanics and Background}

Some of the basic mechanics related to P-delta actions are illustrated in Fig. 1 for a single degree of freedom structure. This consists of a mass, $\mathrm{m}$, with weight force, $\mathrm{P}$, supported by a rigid column with a flexural spring at its base. A dashpot is attached to the mass to allow viscous damping to be included. The stiffness related to the lateral displacement of the mass, due to a horizontal force, $\mathrm{V}$, is $\mathrm{K}_{\mathrm{o}}$ if P-delta actions are neglected. With this model the bending moment, $\mathrm{M}$, acting on the flexural spring is given by -

$$
M=V h+P \delta
$$

where $\mathrm{h}$ is the height of the column and $\delta$ is the lateral deflection of the mass. In this equation the term $\mathrm{P} \delta$ is the bending moment induced by P-delta actions.

A measure that is commonly used to assess the sensitivity of structures to P-delta actions ${ }^{2,3}$ is the stability coefficient, $\theta$. It's numerical value is defined as the ratio of $\mathrm{P}$ delta induced bending moment at some critical section to the corresponding value induced by the lateral design seismic forces. The coefficient is derived assuming that the structure is linearly elastic. For the single degree of freedom model illustrated in Fig. 1, its value is given by -

$$
\theta=\frac{P \delta}{V h},
$$

Associate Professor of Civil Engineering, University of Auckland (Fellow)

Senior Lecturer in Civil Engineering, University of Auckland (Member) which reduces to

$$
\theta=\frac{P}{K_{o} h}
$$

The influence of P-delta actions on a single degree of freedom structure with a bi-linear hysteretic response is illustrated in Fig. 2 for the case of monotonically increasing displacement. If the P-delta actions are excluded, a lateral force of $V_{y}$ is sustained at yield and the subsequent strain hardening stiffness is equal to $\alpha_{\mathrm{sr}} \mathrm{K}_{\mathrm{o}}$. With the P-delta actions included, the effective lateral stiffness is reduced to $\mathrm{K}_{\mathrm{o}}(1-\theta)$ for deflections in the elastic range, and to $\mathrm{K}_{\mathrm{o}}\left(\alpha_{\mathrm{sr}}-\theta\right)$ for deflections in the post elastic range. The area between the lateral force versus displacement traces with and without $P$ delta actions included represents the work done by the loss of height of the weight, $P$.

A consequence of the reduction in stiffness that occurs when P-delta actions are included in an analysis is that the nominal period of vibration increases from $T$ to $T^{\prime}$, where

$$
T^{\prime}=T \frac{1}{\sqrt{1-\theta}} .
$$

As the practical range of stability coefficients lies between zero and 0.2 , the increase in period of vibration is not generally significant in design terms. However, from the point of view of research investigations into P-delta actions, it has important implications. P-delta effects are measured by calculating the difference in structural response of analyses with and without the P-delta actions present. As response spectra for earthquake ground motions are invariably jagged in nature, this small change in period by itself introduces appreciable variability in the difference between two analyses, as illustrated in Fig. 3. Consequently, to determine trends produced due to P-delta effects, a large number of analyses are required. 


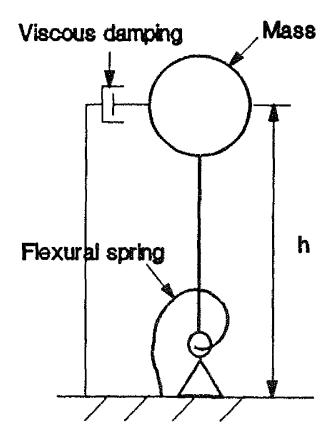

MODE

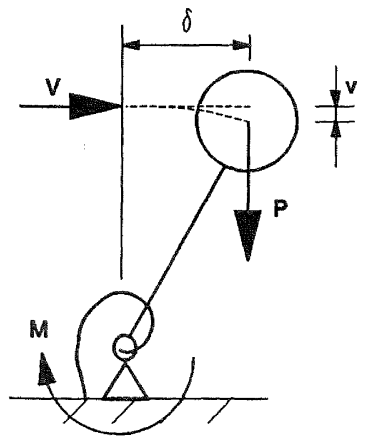

DEFLECTED SHAPE

Figure 1 The basic single degree of freedom model.

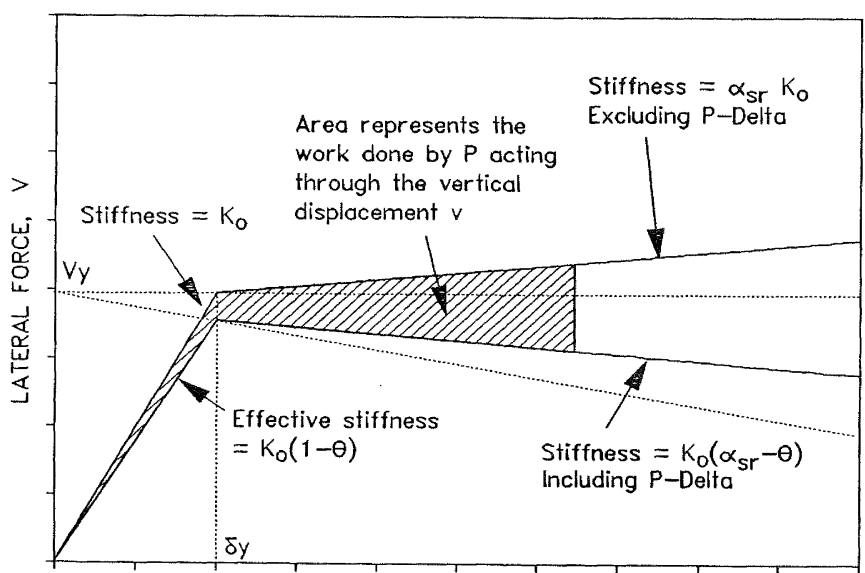

LATERAL DEFLECTION, $\delta$

Figure 2 P-delta effects in a structure subjected to monotonically increasing lateral displacement.

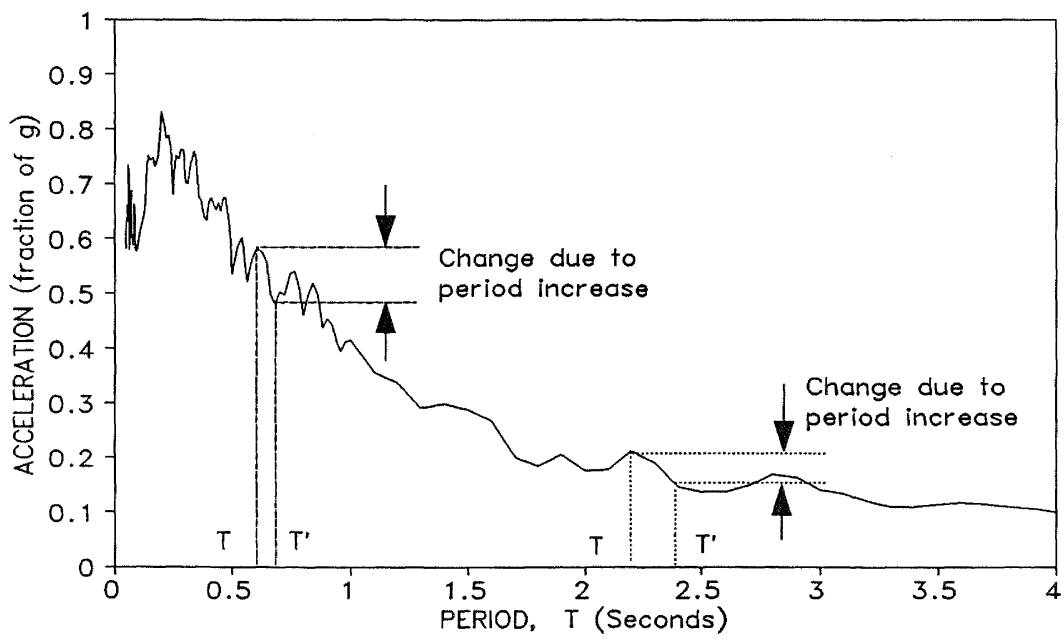

Figure 3 Change in spectral acceleration due to period lengthening. 
The reduction in stiffness of a structure in the inelastic range due to the inclusion of P-delta effects (see Fig. 2) means that each time an inelastic response is included in a structure there is a tendency for the displacement to increase. This is illustrated in Fig. 4, where the results of two time history analyses are shown. In the first one P-delta effects are excluded, while in the second one they are included. The progressive increase in deflection with time is apparent.

To compensate for P-delta effects two different approaches may be used.

(1) The stiffness of the structure may be increased. This reduces the deflection and hence the P-delta induced actions. However, frequently it is not practical or economic to increase the stiffness sufficiently to reduce the actions to the level that they can be ignored in design. Increasing the stiffness generally has the secondary effect of increasing the seismic design actions, as the period of the structure is reduced.

(2) The strength of the structure may be increased. This approach is illustrated in Fig. 5, where the time displacement relationships for single degree of freedom structures with differing yield strengths are shown. It can be seen from this figure that increasing the strength reduces the maximum displacement. This is contrary to the equal displacement concept, which applies to the unrealistic case where P-delta actions are excluded from the analyses.

The analysis results shown in Fig. 5 illustrate the importance of the duration of the severe ground shaking on Pdelta effects. Shown in this figure are three displacement time histories of single degree of freedom systems with P-delta effects acting. The non-dimensionalized yield strength, $V_{y}$, with a value equal to 0.1161 , corresponds to a ductility demand of 6 and a maximum displacement of $0.25 \mathrm{~m}$, when P-delta effects are excluded from the analysis. With the same strength and P-delta effects included, collapse occurs after 12 seconds. However, if the severe ground shaking had stopped after 8 seconds, the maximum deflection would have been $0.25 \mathrm{~m}$ and the behaviour is likely to have been deemed satisfactory. An increase in strength of 43 percent, to give $V_{y}$ a value of 0.1661 , allows the structure to survive with a ductility demand of 6 . The maximum deflection corresponding to this is 0.36 $\mathrm{m}$. A strength increase of 67 percent restricts the maximum deflection to the same value that was obtained when the P-delta effects were neglected, but in this case, the ductility demand would only have been 3.6. With P-delta actions included, the inelastic deflections tend to accumulate in one direction. Consequently, the longer the severe ground shaking continues, the greater is the lateral displacement that is induced.

To determine the significance of P-delta actions in a structure for a given earthquake record two sets of analyses are required. In the first set the P-delta actions are excluded. For a structure with a given period of vibration a number of time history analyses are made with differing yield strengths. By trial and error the yield strength corresponding to a given displacement ductility demand is determined. In the second set of analyses the process is repeated, only in this case the P-delta actions are included in the analyses. The strength is adjusted to maintain the same ductility demand. As the stiffness is not changed, the deflection sustained at first yield increases, and consequently, the maximum deflections increase in proportion to the strength increase.

The results of P-delta actions found from analyses can be assessed in terms of two different factors, as outlined below.

(1) The first factor is known as the amplification factor, $\alpha$. It is equal to the ratio of the yield strength a structure requires for a given ductility demand calculated

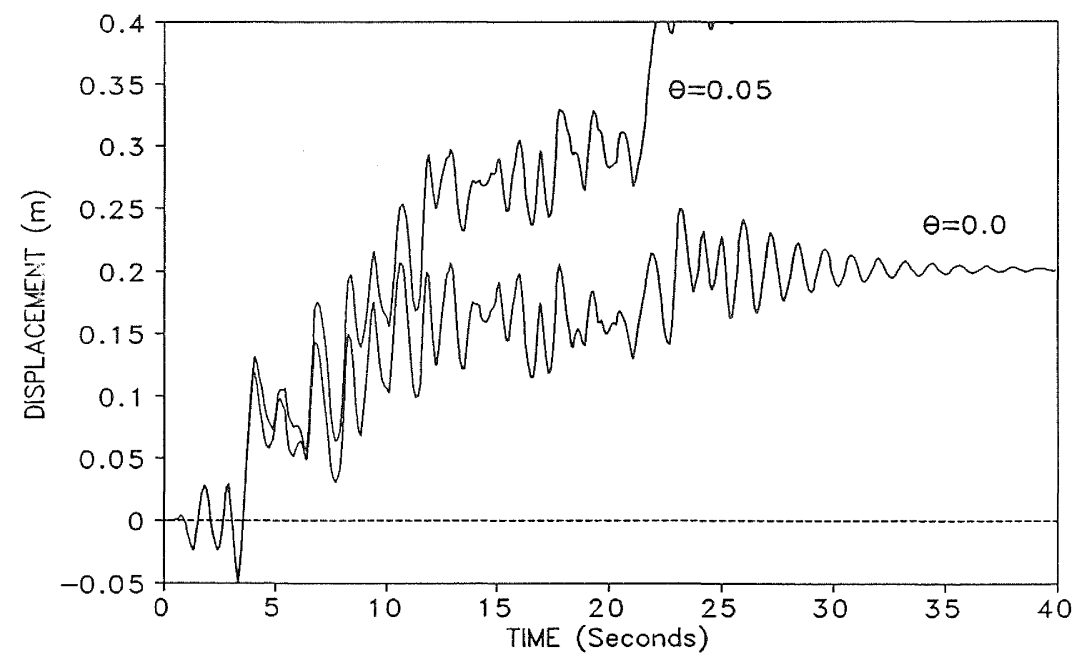

Figure 4 Displacement time history of an inelastic sdof system with and without Pdelta acting. 
including P-delta effects in the analysis, divided by the corresponding yield strength determined neglecting Pdelta actions. Thus for a given ductility, the flexural strength required, $\mathbf{M}^{\prime}$, when $\mathbf{P}$-delta actions are included, is given by -

$$
M^{\prime}=\alpha M,
$$

where $\mathrm{M}$ is the flexural strength found neglecting $\mathrm{P}$ delta actions.

(2) The second factor is the P-delta amplification factor, $\beta$, which is defined by -

$$
M^{\prime}=M+\beta\left(P \delta_{\max }\right),
$$

where $\delta_{\max }$ is the maximum displacement calculated for the given ductility demand neglecting P-delta actions.

From Equations 4 and 5 it follows that -

$$
\alpha=1+\beta \frac{P \delta_{\max }}{M} .
$$

As the maximum displacement, $\delta_{\max }$, is equal to the displacement ductility factor, $\mu$, times the displacement at first yield, $\delta_{y}$, equation 6 may be reduced to -

$$
\beta=\frac{\alpha-1}{\mu \theta} \text {. }
$$

\section{Analyses of Single Degree of Freedom Structures}

Bernal $^{3}$ carried out a large number of analyses to investigate P-delta effects in a systematic manner. $\mathrm{He}$ considered structures with periods which ranged from 0.2 to 2 seconds, in intervals of 0.05 seconds. For each structure, stability coefficients were chosen which ranged from 0 to 0.2 in intervals of 0.025 . In all cases, elastic-perfectly plastic behaviour was assumed together with 5 percent critical viscous damping. Analyses were made for structural ductility factors of $1,2,3,4,5$ and 6 for each of the following ground motions;

$\begin{array}{llll}\text { (i) } & \text { Olympia } & 1965 & \text { S86W } \\ \text { (ii) } & \text { El Centro } & 1940 & \text { S00E } \\ \text { (iii) } & \text { Taft } & 1952 & \text { S69E, and } \\ \text { (iv) } & \text { Pacoima } & 1972 & \text { S16E. }\end{array}$

All these ground motions are representative of firm site conditions, with durations of severe ground motion in the 14 to 26 second range.

Bernal ${ }^{3}$ found that for the range of periods he examined the amplification factors were only weakly correlated with period. Consequently, he averaged the values for the structures with differing fundamental periods for the four earthquake records. He presented tables which gave both the mean amplification factor and the mean plus one standard deviation for the differing ductilities and stability coefficients. His results, which relate the mean amplification factor to the ductility and stability coefficient, are shown in Fig. 6.

From Fig. 6 it can be seen that for a given ductility the variation in mean amplification factor is close to linear with the stability coefficient. Assuming that a linear relationship exists, the corresponding P-delta amplification factor, $\beta$, is found to be a function of the ductility. These values are given in Table 1, together with the values corresponding to the mean plus one standard deviation.

Further single degree of freedom P-delta analyses were made by Panchia ${ }^{4}$ and Chung ${ }^{5}$ at the University of Auckland. Panchia based his work on the El Centro 1940 SOOE earthquake record. Initially, analyses using an elastic-perfectly plastic hysteretic response were run using five percent critical viscous damping. The results obtained from these were found to be identical to values given in Bernal's paper ${ }^{3}$. In subsequent sets of analyses Panchia changed the strain hardening ratio, $\alpha_{\mathrm{sr}}$, and the force deflection characteristic of the structure, to allow for stiffness degradation. Both these factors were found to have only a minor influence on the amplification factors.

Another study into the P-delta response of ductile single degree of freedom structures was made by Mahin and Boroschek $^{11}$. The authors used the same approach of strength enhancement as Bernal ${ }^{3}$, Chung ${ }^{5}$ and Panchia ${ }^{4}$, and also found their results were in good agreement with those of Bernal ${ }^{3}$.

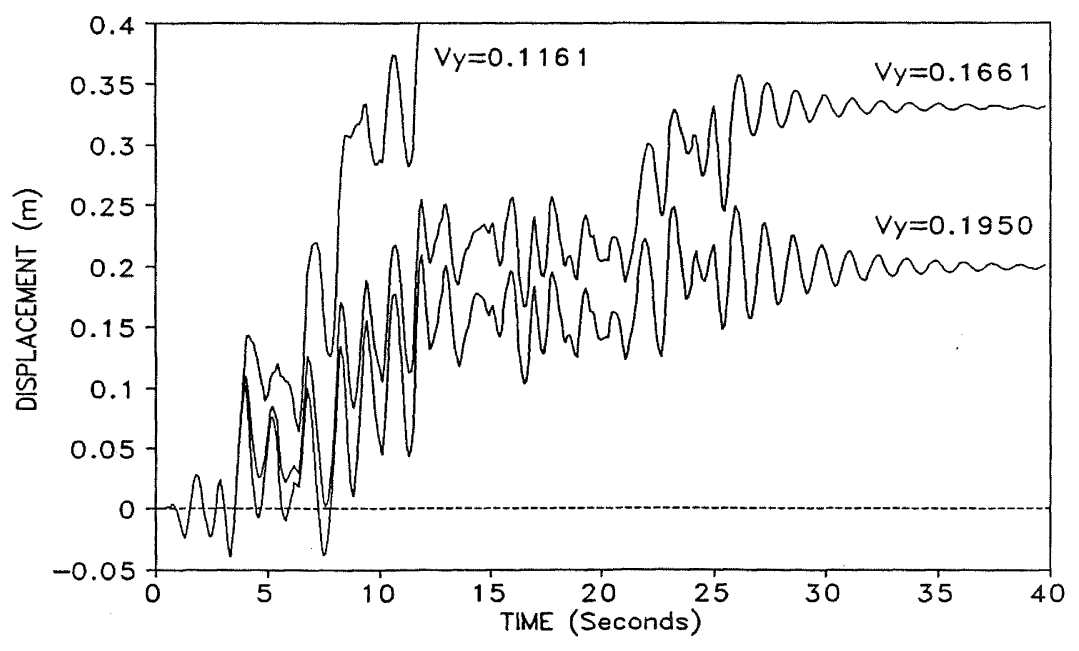

Figure 5 Displacement time histories of an sdof structure with varying nondimensionalized yield strengths $(\Theta=0.1)$. 
Table 1 P-delta amplification factors, B, calculated from Bernal's amplification factors.

\begin{tabular}{||c|c|c|c|c|c|c|}
\hline \multirow{2}{*}{ Item } & \multicolumn{6}{|c|}{ Structural ductility factor } \\
\cline { 2 - 7 } & 1 & 2 & 3 & 4 & 5 & 6 \\
\hline Mean value & 0.58 & 1.12 & 1.73 & 1.89 & 2.05 & 2.23 \\
$\begin{array}{l}\text { Mean value plus } \\
\text { one standard } \\
\text { deviation }\end{array}$ & 1.96 & 2.10 & 2.60 & 2.78 & 2.90 & 3.07 \\
\hline
\end{tabular}

Table 2 Change in P-delta amplification factor with percentage of viscous damping - given as ratios of values obtained with 2,5 and 10 percent".

\begin{tabular}{|c|c|c|c|c|}
\hline \multirow{2}{*}{$\begin{array}{c}\text { P-delta } \\
\text { amplification } \\
\text { factor ratio }\end{array}$} & \multicolumn{4}{|c|}{ Displacement Ductility } \\
\cline { 2 - 5 } & 1 & 2 & 4 & 6 \\
\hline$\beta_{2 \%} / \beta_{5 \%}$ & 1.64 & 1.81 & 1.44 & 1.32 \\
\hline$\beta_{10 \%} / \beta_{5 \%}$ & 0.77 & 0.71 & 0.84 & 0.85 \\
\hline
\end{tabular}

"Ratios based on 720 analysis results using the ART-1 record.

An extensive series of analyses were carried out by Chung ${ }^{5}$. While several different seismic ground motions were used, most of the analyses were made using an artificial record, ART-1, which was developed to have a target response spectrum the same as that given in the draft loadings code ${ }^{1}$ for normal soils. The duration of severe ground motion for the ART-1 record was approximately 25 seconds. Using this record, analyses were carried out for structural ductility factors of $1,2,4$ and 6 , with the period of vibration varying from 0.1 to 4 seconds. The actual periods chosen varied in intervals of 0.1 up to 1 second, and 0.2 between 1 and 2 seconds followed by $2.4,2.8,3.2$ and 4 second values.

From his analyses Chung confirmed the observation made from Bernal's work; that the amplification factor increased linearly with the stability coefficient. The values found with the ART-1 record were very similar in magnitude to those obtained by both Bernal ${ }^{3}$ and Panchia ${ }^{4}$. Varying the strain hardening ratio, $\alpha_{\mathrm{sr}}$, from 0.001 to 0.10 was found to lead to about a 10 percent change in amplification factor, showing this factor is not very significant. However, varying the viscous damping did make a significant difference. Reducing the percentage of critical viscous damping from 10 to 2 percent lead to an increase in P-delta amplification factor of the order of 50 percent for the structural ductility factors of 4 and 6 . The results of the analyses looking at the effect of viscous damping are summarised in Table 2 , while the results of some other series of analyses made by Bernal, Panchia and Chung for structures in the period range of 0.1 to 2 seconds are summarised in Table 3. The number of analysis results is given to enable some assessment to be made of the relative reliability of the values.
Analyses carried out by Chung', in which the energy input and dissipation in the structures were tested, indicated that including P-delta effects in the analysis increased the energy that had to be dissipated by up to 20 percent in ductile structures. The source of this energy was due to the loss in height of the supported mass, as illustrated in Figs. 1 and 2, and it is referred to as P-delta energy.

Previous researchers such as Andrews ${ }^{12}$ and Paulay ${ }^{13}$ have discussed the importance of P-delta energy in terms of design implications. Andrews ${ }^{12}$ proposed a design criteria based on limiting the P-delta energy to a proportion of the energy capacity of the structure under monotonic loading. From the studies of Bernal ${ }^{3}$, Chung ${ }^{5}$, Panchia $^{4}$, and Mahin and Boroschek $^{11}$, however, the most significant factors contributing to the P-delta response of ductile single degree of freedom structures were found to be the ductility demand and the duration of the ground motion. Neither of these factors are reflected in criteria based on P-delta energy.

To obtain some idea of the influence of the duration of severe ground motion on P-delta effects, Chung ${ }^{5}$ determined amplification factors for the Parkfield N65E 1966 earthquake. This ground motion had similar energy contents to the $\mathrm{El}$ Centro and ART-1 records but it was of much shorter duration. The factors were found to be of the order of one third of the corresponding values found using the ART-1 record. This finding indicated that the duration of severe ground motion is a major factor in determining the influence of P-delta effects on ductile structures. Mahin and Boroschek ${ }^{11}$ also conducted a study on the significance of duration on the P-delta response of ductile single degree of freedoms systems using time history analyses. They also concluded that the duration of motion was a very important factor influencing such structures. 
Table 3 P-delta amplification factors, $B$, over a period range of 0.1 to 2 seconds for earthquake records representative of firm sites (average values).

\begin{tabular}{|c|c|c|c|c|c|c|c|c|c|c|c|c|c|}
\hline \multirow[t]{2}{*}{ Investigator } & \multirow[t]{2}{*}{ Eq. record } & \multirow{2}{*}{$\begin{array}{c}\text { Strain } \\
\text { hardening, } \\
\alpha_{\mathrm{sr}}(\%) \\
\end{array}$} & \multirow{2}{*}{$\begin{array}{l}\text { Hysteretic } \\
\text { response }\end{array}$} & \multirow{2}{*}{$\begin{array}{c}\text { Stability } \\
\text { coefficient, } \\
\theta \\
\end{array}$} & \multirow{2}{*}{$\begin{array}{c}\text { Period } \\
\text { (seconds) }\end{array}$} & \multirow{2}{*}{$\begin{array}{c}\text { Viscous } \\
\text { damping } \\
(\%)\end{array}$} & \multicolumn{6}{|c|}{ Displacement Ductility } & \multirow{2}{*}{$\begin{array}{c}\text { No. of } \\
\text { Analysis } \\
\text { Results }\end{array}$} \\
\hline & & & & & & & 1 & 2 & 3 & 4 & 5 & 6 & \\
\hline Bernal $^{3}$ & 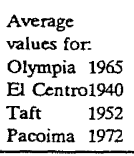 & 0 & bi-linear & $\begin{array}{c}0.025-0.2 \\
\text { in } \\
8 \text { steps }\end{array}$ & $\begin{array}{l}0.2-2.0 \\
\text { for } \\
36 \text { values }\end{array}$ & 5 & 0.58 & 0.12 & 1.73 & 1.89 & 2.05 & 2.23 & 6900 \\
\hline \multirow[t]{3}{*}{ Panchia $^{4}$} & El Centro & $\begin{array}{c}2.5 \\
0\end{array}$ & bi-linear & $\begin{array}{l}0.1 \\
0.1\end{array}$ & $\begin{array}{c}0.1-2.0 \\
\text { for } \\
15 \text { values }\end{array}$ & 5 & 0.70 & 0.87 & & $\begin{array}{l}1.07 \\
1.29\end{array}$ & & 1.24 & $\begin{array}{l}60 \\
15\end{array}$ \\
\hline & El Centro & $\begin{array}{l}0.1 \\
2.5 \\
5.0 \\
\end{array}$ & bi-lineat & $\left.\begin{array}{l}0.05 \\
0.10 \\
0.20\end{array}\right\}$ & 1.0 & 5 & $\begin{array}{l}-0.50 \\
-0.36 \\
-0.33 \\
\end{array}$ & $\begin{array}{l}0.49 \\
0.45 \\
0.29 \\
\end{array}$ & & $\begin{array}{l}1.07 \\
0.89 \\
0.75 \\
\end{array}$ & & $\begin{array}{l}1.23 \\
1.11 \\
1.07 \\
\end{array}$ & 36 \\
\hline & El Centro & $\begin{array}{l}0.1 \\
25 \\
5.0 \\
\end{array}$ & $\begin{array}{l}\text { degrading } \\
\text { stiffness }\end{array}$ & $\left.\begin{array}{l}0.05 \\
0.10 \\
0.20\end{array}\right\}$ & 1.0 & 5 & $\begin{array}{l}-0.47 \\
-0.30 \\
-0.58 \\
\end{array}$ & $\begin{array}{l}0.43 \\
0.43 \\
0.41 \\
\end{array}$ & & $\begin{array}{l}1.03 \\
0.85 \\
1.02 \\
\end{array}$ & & $\begin{array}{l}0.86 \\
0.86 \\
1.11 \\
\end{array}$ & 36 \\
\hline Chung $^{5}$ & ART-1 & 2.5 & bi-linear & $\begin{array}{c}0.025 \rightarrow 0.2 \\
\text { in } \\
8 \text { steps }\end{array}$ & $\begin{array}{c}0.2-2.0 \\
\text { for } \\
15 \text { values }\end{array}$ & 5 & 0.63 & 0.86 & & 1.66 & & 1.68 & 480 \\
\hline Chung* & El Centro & 2.5 & bi-linear & $0.1, \quad 0.15$ & $\begin{array}{l}0.2-2.0 \\
\text { for } \\
15 \text { values }\end{array}$ & 5 & & 1.24 & & 1.24 & & 1.51 & 90 \\
\hline
\end{tabular}

-Values not yet published.

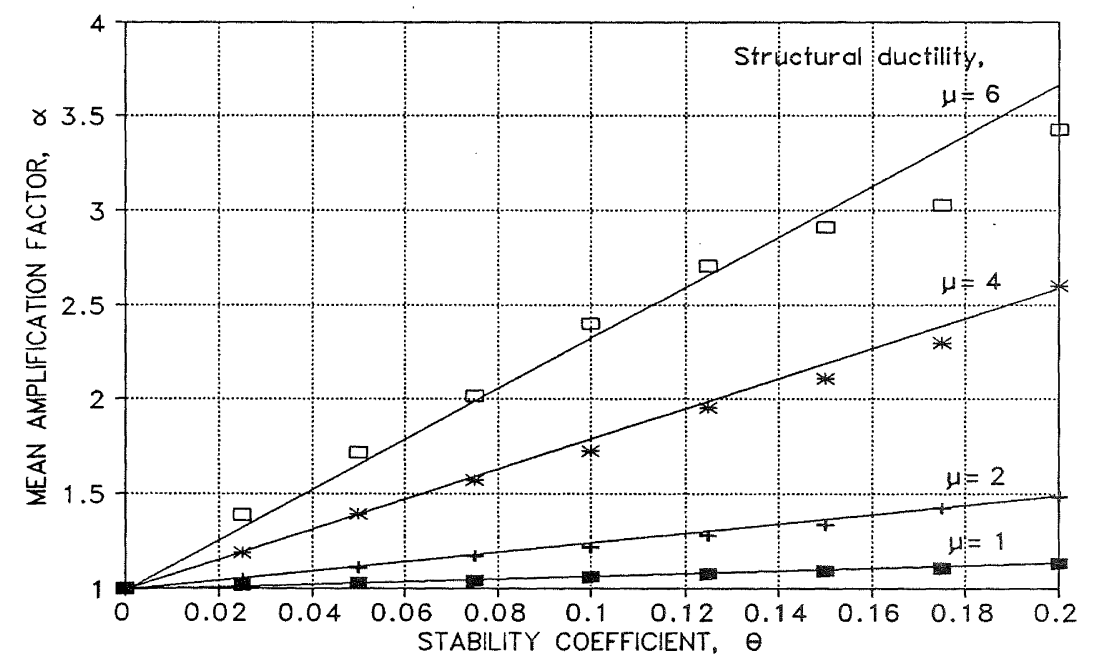

Figure 6 Variation of amplification factor with structural ductility factor and stability coefficient after Bernal ${ }^{3}$.

Chung's and Panchia's results tended to confirm Bernal's observation that the amplification factor was only weakly correlated to period in the range of 0.1 to 2 seconds. However, for longer periods with the ART-1, El Centro and Parkfield records their results showed that there is a marked decrease in P-delta effects as the period increases above two seconds. Fig. 7 illustrates the variation of the P-delta amplification factors with period for the ART-1 ground motion for structures with structural ductility factors of 4 and 6 . Each point on this figure represents an average of 8 values found for stability coefficients which varied in the range of 0.025 to 0.2 .

Fig. 8 shows the variation in P-delta amplification factor with period for several different ground motions. The analyses are for a stability coefficient of 0.1 and a structural ductility factor of 6. The ART-1 and Parkfield records show a marked decrease in P-delta effects as the period increases above 2 seconds. With the El Centro record the P-delta effects decrease for periods greater than one second, but not to the extent seen with the other two ground motions. The results obtained with the Mexico City N90W earthquake record (1985), which was obtained at a site with deep flexible subsoils, and had a duration of intense shaking in excess of 2 minutes, shows very different trends from the other earthquake records that are representative of sites with firm subsoil conditions. With the Mexico City record, the P-delta amplification factors reached about three times the maximum magnitudes obtained with the ART-1 and El Centro ground motions. This is believed to be due to the relative durations of the earthquakes, while the location of the peak in the P-delta amplification factors is thought to be a function of the site conditions, which concentrated the energy of the earthquake into the 1.5 to 3 second region of the spectrum ${ }^{5}$. For the El Centro, Parkfield and ART-1 records, the maximum energy is in the 0.5 to 2.5 second region. 


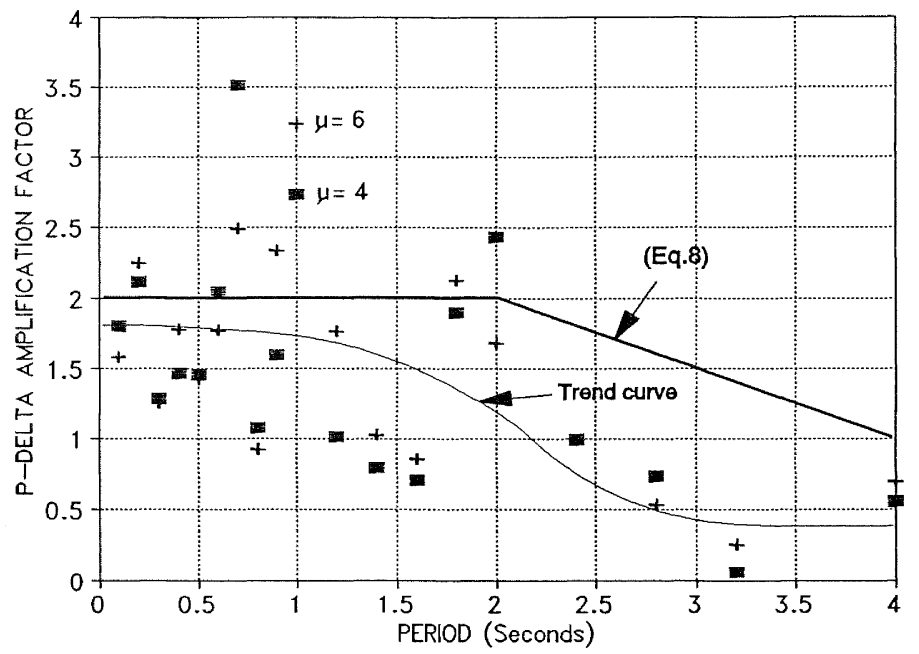

Figure 7 Variation of average P-delta amplification factors, $B$, for stability coefficients in the range of 0.025 to 0.2 with period, for the ART- 1 ground motion.

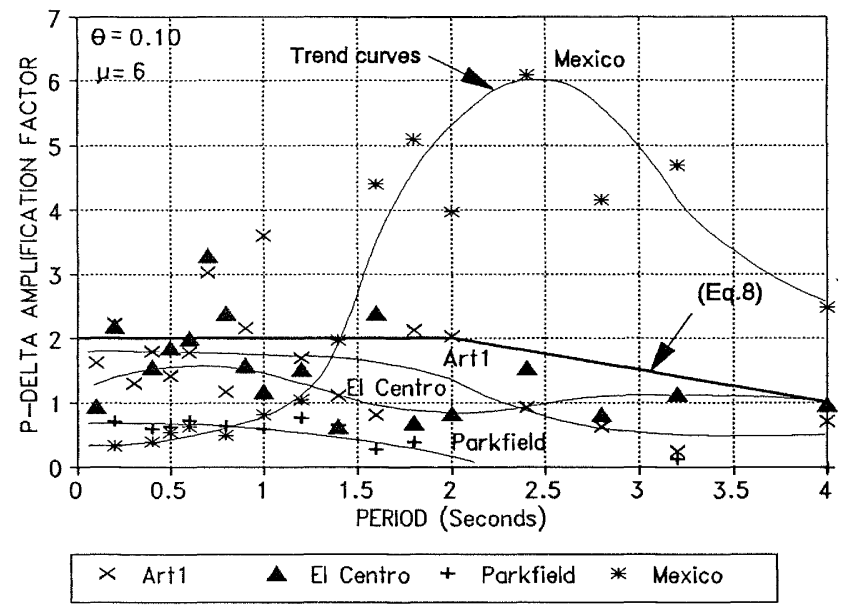

Figure 8 Variation of amplification factor for different ground motions with period.

The average values for the P-delta amplification factor for different period ranges are given in Table 4 for the ART-1 and $\mathrm{El} \mathrm{Centro} \mathrm{ground} \mathrm{motions.} \mathrm{These} \mathrm{values} \mathrm{confirm} \mathrm{that} \mathrm{the}$ observed decrease in P-delta amplification factor with period for structural ductility factors of 4 and 6 , which was shown in Figs. 7 and 8 , occurs for the full range of structural ductility factors.

\section{P-delta Amplification Factors for Single Degree of Freedom Structures}

In this section, equations are developed for P-delta amplification factors for single degree of freedom structures. The values are intended to be compatible with the draft loadings code (DZ-4203-91) ${ }^{1}$, with the duration of the severe ground motion in the design level earthquake being in the range of 15-25 seconds. This corresponds to the range used by Bernal $^{3}$ and Chungs.
In Fig. 9 the average P-delta amplification factors for the period range of 0.1 to 2 seconds are shown for different structural ductility factors. It should be noted that the points plotted on this figure, which have been taken from Bernal's ${ }^{3}$ research, are based on many more values than those from the work of Chung. It is suggested that two straight lines may be fitted to these results to give a reasonable estimate of the variation of P-delta amplification factor with structural ductility. In view of the spread of values a more accurate fit of equations is not justified. For this period range the equations are;

$$
\begin{array}{rlrr}
\beta & =\frac{2 \mu}{3.5} \text { for } 1.0<\mu<3.5, \\
& =2.0 \text { for } \quad \mu>3.5 .
\end{array}
$$


Table 4 Variation of P-delta amplification factor with period range, for the ART-1 and $\mathrm{El} \mathrm{Centro} \mathrm{ground} \mathrm{motions.}$

\begin{tabular}{||c|c|c|c|c|c||}
\hline \multirow{2}{*}{$\begin{array}{c}\text { Ground } \\
\text { Motion }\end{array}$} & \multirow{2}{*}{$\begin{array}{c}\text { Period } \\
\text { Range } \\
\text { (Seconds) }\end{array}$} & \multicolumn{4}{|c||}{ Structural Ductility Factor } \\
\cline { 3 - 6 } & 1 & 2 & 4 & 6 \\
\hline ART-1 & $0.1-2.0$ & 0.63 & 0.86 & 1.66 & 1.68 \\
(Chung) $^{5}$ & $0.1-0.9$ & 0.84 & 1.24 & 1.80 & 1.72 \\
& $1.0-1.8$ & 0.22 & 0.64 & 1.47 & 1.80 \\
& $2.0-4.0$ & 0.42 & 0.76 & 0.95 & 0.83 \\
& & & & & \\
El Centro & $0.1-2.0$ & & 1.24 & 1.24 & 1.51 \\
(Chung*) $^{*}$ & $0.1-0.9$ & & 1.72 & 1.76 & 1.95 \\
& $1.0-1.8$ & & 0.75 & 0.88 & 1.22 \\
& $2.0-4.0$ & & 0.85 & 1.17 & 1.04 \\
\hline
\end{tabular}

*Values not yet published.

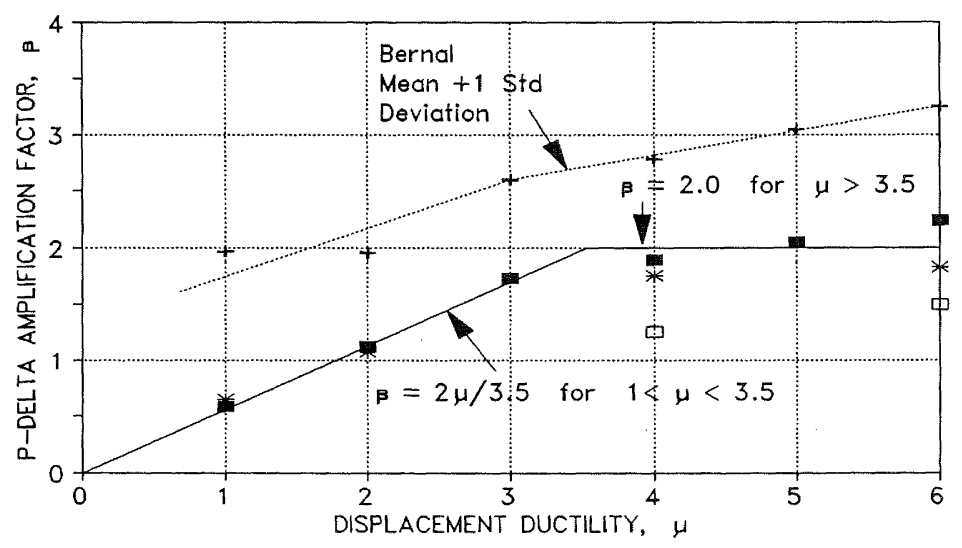

- Bernal(Mean) + Bernal(Mean+1Std) $*$ Art1

Figure 9 P-delta amplification factors averaged over a period range of 0.1 to 2.0 seconds.

The points plotted for the mean value plus one standard deviation from Bernal's work gives an idea of the spread of the individual results. Approximately 84 percent of the P-delta amplification factors calculated should lie below this line. For structural ductility factors in the range of 3 to 6 , the standard deviation of the amplification factors is about 45 percent of the mean value.

As discussed in the previous section for sites with firm subsoils, the amplification decreases as the period increases above 2 seconds. To allow for this influence the value of $\beta$ should be multiplied by $K_{\mathfrak{l}}$, where -

$$
\begin{aligned}
\mathrm{K}_{\mathrm{t}} & =1.0 & \text { for } & \mathrm{T} \leq 2.0 \text { seconds } \\
& =\frac{6-\mathrm{T}}{4} & \text { for } & 2.0<\mathrm{T} \leq 4.0 \text { seconds } \\
& =0.5 & \text { for } & \mathrm{T}>4.0 \text { seconds }
\end{aligned}
$$

Analyses have not been run for earthquake records representative of sites with flexible subsoils. However, from the results of analyses using the Mexico City earthquake, it is evident that the period range in which the maximum P-delta amplification factors lie is closely related to the range that contains the greatest energy content. On this basis, it is evident that the $K_{t}$ values should be modified for sites with flexible subsoils. For such conditions the following values are proposed -

$$
\begin{array}{rlrrr}
\mathrm{K}_{\mathrm{t}} & =1.0 & \text { for } & \mathrm{T} \leq 2.5 \text { seconds }, \\
& =\frac{6.5-\mathrm{T}}{4} \text { for } & 2.5<\mathrm{T} \leq 4.5 \text { seconds } \\
& =0.5 & \text { for } & \mathrm{T}>4.5 \text { seconds }
\end{array},
$$

Further research is required to establish the appropriate values of $\mathrm{K}_{\mathrm{t}}$ for sites with flexible and soft subsoil conditions. 
In summary, a single degree of freedom structure subject to P-delta actions requires the flexural spring at the base of the column supporting the seismic mass to have an average yield strength of;

$$
M=V h+K_{t} \beta\left(P \delta_{\max }\right) .
$$

This value applies for structures with 5 percent critical viscous damping. Where a different level of viscous damping is appropriate an assessment of the change in the $\beta$ value that should be applied may be made from the values given in Table 2.

\section{Multi-storey Structures}

A number of questions arise in applying the design method obtained in the previous section for single degree of freedom structures to multi-storey structures. One of these relates to the deflected shape that should be used for calculating the P-delta actions. For the single degree of freedom structure there is only one form of deflected shape, as all the deformation occurs in the base spring. However, as soon as more than one degree of freedom exists, different forms of deflected profile are possible. A limited number of analyses carried out by Chung ${ }^{5}$ indicates that the deflected shape envelope found in a modal response spectrum analysis gives a reasonable base for P-delta calculations. This envelope is generally within a few percent of the profile obtained from the first mode response. Scaling the modal response spectrum deflection at the top of the structure by the structural ductility factors has been found to give a reasonable estimate of the deflection that may be expected at this point ${ }^{6,7}$. However, using the same scale factor at lower levels can lead to a major under-estimate of the lateral deflections obtained in time history analyses. The discrepancy increases with the structural ductility factor and the fundamental period of the building?. It should be noted that P-delta effects accumulate in a structure throughout the earthquake and with each increment, a different deflected profile applies. Consequently, there can be no single theoretical profile.

In many previous projects in which P-delta effects have been investigated, the significance of the ductility demand has not been appreciated. Often, structures which have been analysed for P-delta effects, have been given strengths that were considerably in excess of the minimum values corresponding to the design ductility level for the earthquake ground motion used in the analysis. A consequence is that the actual ductility demand is appreciably less than that implied by the seismic design forces.

Frequent sources of excess strength in models used for research into P-delta actions in multi-storey structures are outlined below.

(1) Structures are often analysed and designed to a codespecified response spectrum. The ordinate of this spectrum at the fundamental mode, in some cases, is appreciably greater than the corresponding ordinate of the response spectrum for the ground motion used in the time history analysis.

(2) The method of analysis that is chosen for the design of the structure may not be the one that gives the minimum strengths permitted by the code. For both frame and wall structures, an analysis based on the modal response spectrum method gives smaller critical design actions than the corresponding values based on the equivalent static method. For example, for an 18 storey frame, the base shear and overturning moment found by the equivalent static method are 15 and 30 percent in excess, respectively, of the corresponding values found with a modal response spectrum analysis ${ }^{7}$.

(3) Critical members may be given strength in excess of seismic requirements because:-

(i) load combinations not involving seismic actions are critical, or

(ii) allowance is not made for the redistribution of gravity induced actions when plastic hinges form in the beams of frame structures ${ }^{8}$. This is a very frequent cause of excess strength in frame structures, which have been designed for the dual purpose of providing lateral seismic resistance and support for gravity loads.

(4) The potential plastic hinge zones are not correctly located. Frequently it is assumed that the beams will only form plastic hinges at the column faces. In practice, with many frames that are designed to resist gravity loads and provide lateral seismic resistance, plastic hinge zones can develop in the span. Neglecting these hinges in dynamic time history analyses results in the modelled structure being given extra strength.

Analyses of multi-storey structures which do not incorporate additional strength in excess of the minimum required level have not been found in the literature.

\section{Assessment of P-delta Effects in Multi-storey Buildings}

P-delta actions in a series of frames and walls, which were used to provide the seismic resistance in a number of multi-storey structures, were investigated for time history analyses using the ART- 1 ground motion ${ }^{5}$. Initially, each structure was analysed neglecting P-delta effects. The analyses were then repeated several times for each structure with the Pdelta effect included. With each of these repeat analyses the yield strength of the potential plastic hinge zones was increased until the performance of the strength-enhanced structure was judged to be equivalent to its performance assessed from the analysis made with P-delta actions excluded.

The idealised section plan, which was used for all the multi-storey structures, is shown in Fig. 10. The seismic actions in the $\mathrm{X}$ direction were considered and torsional actions were neglected. The lateral force resistance was provided by either reinforced concrete perimeter frames or walls located on lines 1 and 5. The internal framing was assumed to support the gravity loads but provide no lateral resistance. The arrangement of the precast flooring was such that the beams of the perimeter frames on lines 1 and 5 were not subjected to any significant gravity loading. This arrangement was used to avoid any complications arising from redistribution of gravity load actions ${ }^{8}$. With these assumptions the behaviour of the walls and frames could be modelled using the $2 \mathrm{D}$ analysis program DRAIN-2DX?. 


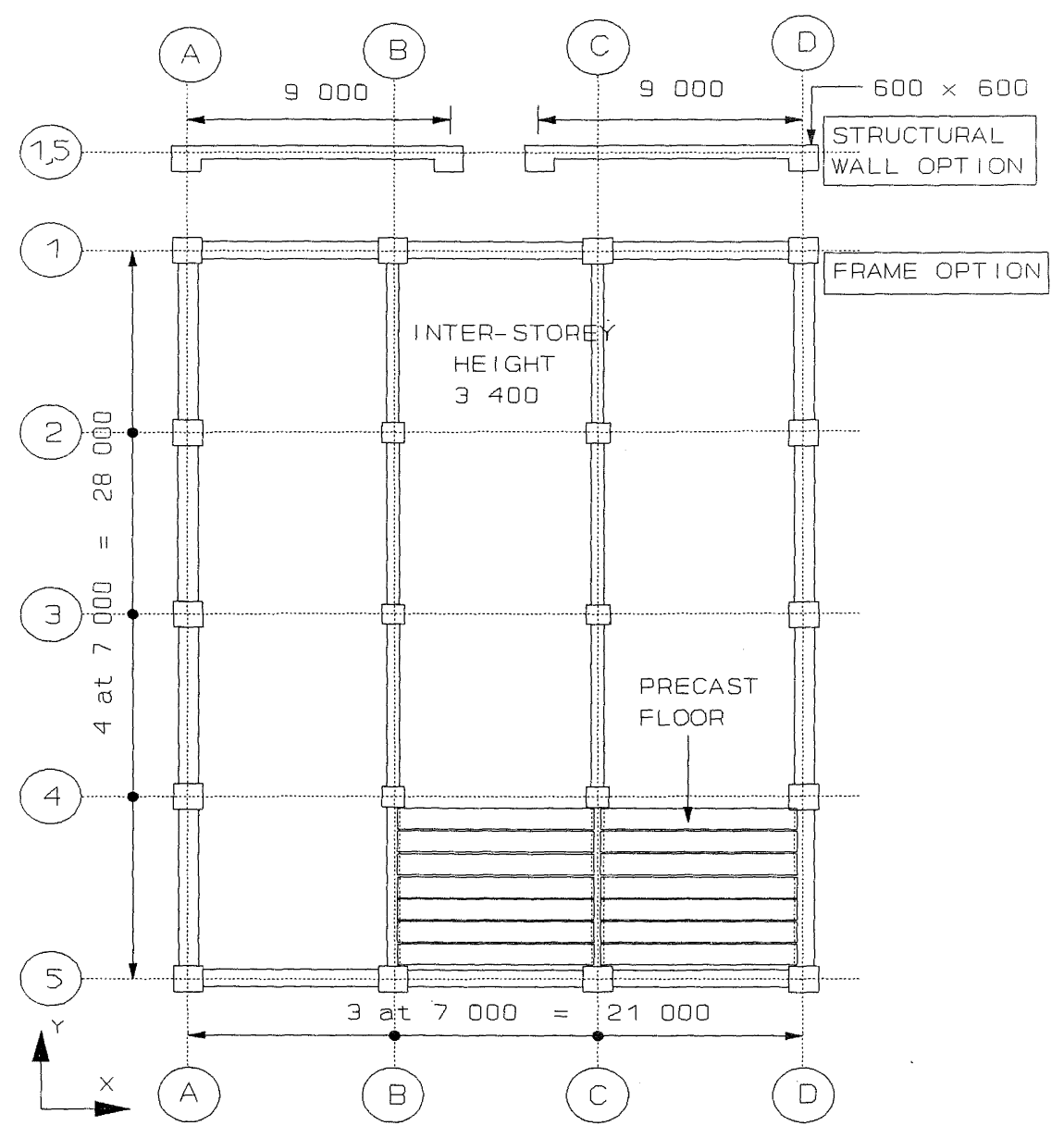

Figure 10 Typical floor plan of building.

The influence of large deflections was then investigated using the computer program ANSR-III ${ }^{14}$. It was found that for interstorey deflections of the magnitudes allowed for by existing $\operatorname{codes}^{1,2}$, the DRAIN-2DX and ANSR-III programs gave effectively the same results. This conclusion is supported by the results obtained by Thomson et al. ${ }^{15}$.

The walls were assumed to be uncoupled. The flexural strengths at the base of the walls for the analyses, where Pdelta actions were excluded, were made equal to the values found from modal response spectrum analyses. The modal contributions were combined by the square root of the sum of the squares. The flexural strength distribution up the wall complied with the requirements for capacity design set out in commentary to the concrete code ${ }^{10}$.

The frames were designed so that column sway modes could not develop. Plastic hinging was restricted to the beams at the columns faces and to the column bases. For the analyses in which P-delta actions were excluded, the flexural yield strengths of the beams were taken as equal to the combined modal bending moments found from modal response spectrum analyses. In compliance with the capacity design recommendations ${ }^{10}$, the yield strengths of the columns at the base level was taken as $0.9 \times 1.4$ times the combined modal bending moment at this point. The 0.9 factor is applied to convert the ideal flexural strength, which is given as $1.4 \mathrm{x}$ $\mathbf{M}_{\text {code }}$ in the recommendations, to a dependable strength.
For all the frames and walls the equivalent of 5 percent viscous damping was applied to the first two modes. The strain hardening characteristics of the potential hinge zones were specified to give the structures a stiffness of $2^{1 / 2}$ percent of its initial stiffness when it was subjected to a set of equivalent static forces, which were scaled to a magnitude sufficient to form all the plastic hinges necessary for a sway mechanism ${ }^{7}$.

The distribution of strength added to the different structures to counter P-delta actions, was based on the actions induced by gravity loads when the structure was deformed into the deflected profile given by the modal response spectrum analysis, scaled by the structural ductility factor. These were defined as the " $\beta=1.0 "$ strengths for the structures. These strengths were then multiplied by the trial P-delta amplification factor. The resultant values were then added to the flexural strengths used in the analysis in which P-delta actions were excluded, to give the trial enhanced strengths. The analyses were repeated with different amplification factors until the ductility demand was judged to be the same as that obtained in the corresponding analysis in which P-delta effects were excluded.

For the walls the ductility demand was based on the deflection at the top of the structure. For the frames it was judged both on the deflection of the top level and the interstorey deflection. In all cases the level of ductility was 
maintained, and consequently, allowance was made for the increases in yield deflection associated with strengthenhancement. For the frame structures the two criteria lead to very similar P-delta amplification factors. Hence, only the average value has been listed in Table 6 .

The buildings, where the structural walls were used to provide the seismic resistance, were found to be relatively insensitive to P-delta effects. The P-delta amplification factors for the walls are listed in row 7 of Table 5. These values can be compared with the corresponding factors found from the single degree of freedom analyses with the same fundamental period, which are given in row 4 .

It can be seen from Table 5 that the predicted increase in strength of the base of the wall required to compensate for P-delta actions is small for the 12 to 30 storey walls. For these structures it is comparable to the increase in strength provided due to the contribution of the higher mode effects. The FD30 wall, which was a slender flexible structure, however, shows a considerably higher increase, with a 23 percent strengthenhancement required.
The P-delta amplification factors required for the frames are compared with the corresponding values predicted by the single degree of freedom analyses using the actual frame properties, as given in rows 4 and 7 in Table 6 . In order to allow absolute values of strength and strength increase to be compared, the average beam seismic shear has been calculated for the lower $1 / 3$ rd of the levels in each frame. The values corresponding to the results of the modal analysis, neglecting P-delta actions, are given in row 2 of the table, with the contribution of the first mode to these values being noted in row 3. The predicted increase in value to compensate for $P$ delta actions is given in row 5 while the value determined from the enhanced strength analysis is given in row 8 .

The values given in Table 6 show that the frames are much more sensitive to P-delta actions than the walls. While for the walls the actual strength increase was only a few percent, except for the FD30 wall, it can be seen that for the frames the comparable value is between 8 and 61 percent. Given the spread of results evident in the single degree of freedom analyses the agreement between the predicted P-delta

Table 5 P-delta effect in walls.

\begin{tabular}{|c|c|c|c|c|c|c|}
\hline \multicolumn{2}{|r|}{ Item } & \multicolumn{5}{|c|}{ Stories } \\
\hline & & \multirow{2}{*}{$\frac{12}{0.73}$} & \multirow{2}{*}{$\frac{18}{1.53}$} & \multirow{2}{*}{$\frac{24}{2.76}$} & \multirow{2}{*}{$\frac{30}{4.28}$} & \multirow{2}{*}{$\frac{\text { FD30 }}{5.29}$} \\
\hline 1 & $\begin{array}{l}\text { Fundamental period } \\
\text { (seconds) }\end{array}$ & & & & & \\
\hline 2 & $\begin{array}{l}\mathrm{M}_{\text {base }} \text { from modal response } \\
\text { spectrum analysis }(\mathrm{kNm})\end{array}$ & 24440 & 24540 & 25380 & 26340 & 21627 \\
\hline 3 & $\begin{array}{l}\text { Proportion of } 1 \text { st mode } \\
\text { contribution to base moment }\end{array}$ & 0.99 & 0.97 & 0.93 & 0.90 & 0.88 \\
\hline 4 & $B$ predicted from sdof analysis & 0.53 & 0.33 & 0.48 & 0.60 & 0.55 \\
\hline 5 & Predicted increase in $\mathrm{M}_{\text {base }}(\mathrm{kNm})$ & 280 & 535 & 1803 & 4308 & 4868 \\
\hline 6 & $\begin{array}{l}\% \text { predicted increase in base } \\
\text { moment }\end{array}$ & 1.1 & 2.2 & 7.1 & 16.4 & 23.3 \\
\hline 7 & $B$ required for $P$-delta & 0.72 & 0.36 & 0.38 & 0.63 & 0.57 \\
\hline 8 & Required increase in $\mathrm{M}_{\text {base }}(\mathrm{kNm})$ & 380 & 584 & 1428 & 4523 & 5044 \\
\hline
\end{tabular}

Table 6 P-delta effect in frames.

\begin{tabular}{|c|c|c|c|c|c|c|}
\hline \multicolumn{2}{|r|}{ Item } & \multicolumn{5}{|c|}{ Stories } \\
\hline & & \multirow{2}{*}{$\frac{3}{1.02}$} & \multirow{2}{*}{$\frac{6}{1.76}$} & \multirow{2}{*}{$\frac{12}{2.55}$} & \multirow{2}{*}{$\frac{18}{3.01}$} & \multirow{2}{*}{$\frac{24}{3.33}$} \\
\hline 1 & $\begin{array}{l}\text { Fundamental period } \\
\text { (seconds) }\end{array}$ & & & & & \\
\hline 2 & $\begin{array}{l}\text { Average seismic shear in } \\
\text { beams on lower } 1 / 3 \text { of levels } \\
(\mathrm{kN})\end{array}$ & 36.8 & 45.6 & 58.7 & 73.4 & 89.3 \\
\hline 3 & $\begin{array}{l}\text { Proportion of } 1 \text { st mode } \\
\text { contribution to seismic shear }\end{array}$ & 0.99 & 0.99 & 0.97 & 0.95 & 0.93 \\
\hline 4 & $\begin{array}{l}B \text { predicted from sdof } \\
\text { analysis }\end{array}$ & 2.77 & 0.73 & 0.61 & 0.36 & 0.20 \\
\hline 5 & $\begin{array}{l}\text { Predicted increase in } \\
\text { average seismic shear in } \\
\text { lower } 1 / 3 \text { of levels }(\mathrm{kN})\end{array}$ & 22.4 & 12.5 & 18.0 & 12.5 & 7.3 \\
\hline 6 & $\%$ increase in seismic shear & 60.8 & 27.4 & 30.7 & 17.0 & 8.2 \\
\hline 7 & $B$ required for $P$-delta & 2.02 & 0.59 & 0.71 & 0.23 & 0.37 \\
\hline 8 & $\begin{array}{l}\text { Required increase in } \\
\text { average seismic shear }(\mathrm{kN})\end{array}$ & 16.4 & 10.1 & 21.0 & 7.9 & 13.4 \\
\hline
\end{tabular}


amplification factors and the values determined from the strength enhanced analyses is satisfactory.

From these analyses it is considered that the method of assessing the strength increase necessary to counter P-delta effects in single degree of freedom structures may be applied to multi-storey structures.

\section{Design for P-delta Actions in Multi-storey Structures.}

In this section the steps that may be followed to design a multi-storey structure, incorporating an allowance for P-delta actions for the strength limit state, are outlined. The approach assumes that column sway mechanisms cannot occur except in the upper two storeys.

\section{Step 1.}

Analyse the structure by the equivalent static or modal response spectrum method neglecting P-delta actions. Results obtained from the equivalent static approach are conservative compared with corresponding values found from the modal method.

\section{Step 2.}

From the analysis in step 1 find the lateral deflections, $\delta_{i}$, of the centroid of the seismic masses at each level, i. For the modal response spectrum method this corresponds to an envelope of deflected profiles.
Step 3.

Multiply the lateral deflections, $\delta_{i}$, found in step 2 by the structural ductility factor. An analysis is now required to determine the structural actions that are induced when the gravity loads are displaced by the amounts defined in step 2 . The results of this analysis are used to define the distribution of the additional strength required to compensate for P-delta actions in the structure.

One method of carrying out this analysis is as outlined in the following paragraphs. The structure is required to fulfil two functions, namely to support the gravity loads and to provide lateral resistance to seismic action. The origin of Pdelta effects can be readily seen if the structure is visualized as having two different types of elements, one for each of the above functions. With this arrangement, a column which is pinned at each floor level, can be assumed to support the gravity loads, as illustrated in Fig. 11. When this column is displaced into the defined deflected shape the inclined compression forces in the columns need to be balanced by shear forces in the structural elements providing the lateral seismic resistance.

A way for finding the P-delta actions induced in the lateral force resisting members is to determine the lateral forces, which must be applied at each floor level, to hold the column in the deflected profile. The lateral force, $F_{i}$, at any level is equal to the difference in the horizontal components of the inclined gravity load resisting members in the adjacent levels.

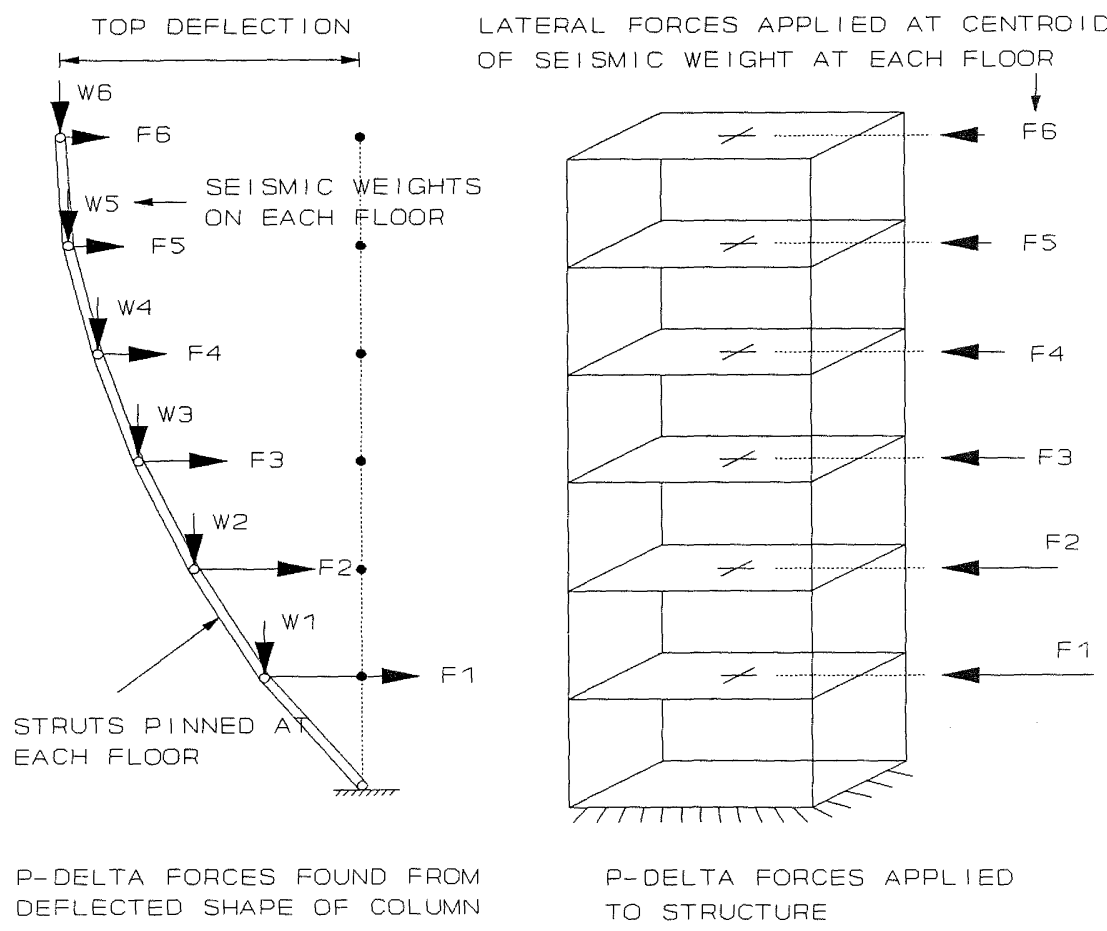

Figure 11 Truss model to determine P-delta equivalent lateral forces. 
An analysis of the structure is carried out with the set of lateral forces, $F_{i}$, being applied to their respective mass centroids at each level. From this a set of internal forces equivalent to those resulting from P-delta actions are obtained. These internal forces are defined as the " $\beta=1$ " strengths of the structure.

Step 4.

Determine the P-delta amplification factor, $\beta$, from equation 8 , together with the value of $K_{1}$ from equation 9 , where normal soil conditions are appropriate, or from equation 10 , where there are flexible subsoils. Where necessary, modify the $\beta$ factor to allow for changes in equivalent viscous damping. Scale the " $\beta=1 "$ strengths found in step 3 by the $\mathrm{K} \beta$ factor.

\section{Step 5}

Add the structural actions found in step 4, to the values found in step 1 , to give the total design seismic actions, which may now be used in the specified load combinations to determine the actual design actions. For ductile structures, redistribution may be applied, provided equilibrium requirements are not violated.

\section{Conclusions}

The results of analyses of single degree of freedom structures with different earthquake ground motions shows that the factors described in the following list have a major influence on the effects of P-delta actions.

(1) P-delta effects increase with the stability coefficient.

(2) Generally, P-delta effects are negligible in elastically responding structures, from the design point of view, but they increase with the ductility demand.

(3) P-delta effects increase with the duration of intense ground shaking.

(4) Reducing the equivalent viscous damping increases the P-delta effects.

(5) P-delta effects reduce as the period of the structure increases beyond 2 seconds, but there is little systematic influence for period changes within the range of 0.2 to 2 seconds, for ground motions representative of firm sites.

Analyses showed that changing the hysteretic response to allow for stiffness degradation, and changing the strain hardening ratio, have only a small influence on the P-delta response of ductile single degree of freedom structures.

Based on the analyses of single degree of freedom structures, for earthquake ground motions with durations of severe ground shaking in the 15 to 25 seconds range, a method of assessing the strength increase necessary to prevent the ductility demand increasing when P-delta effects are included, is given. The required strength increase is determined in terms of the P-delta amplification factor, $\beta$, and a factor $\mathrm{K}_{\mathrm{t}}$, which allows for the influence of fundamental period and soil type.
Analyses of multi-storey structures indicate that the deflected shape envelope found on a modal response spectrum analysis, may be used to calculate the distribution of additional strengths required to counter P-delta actions.

A series of multi-storey walls and frames were analysed to obtain P-delta amplification factors. The corresponding single degree of freedom values were also calculated using the respective wall and frames properties. From these analyses it was concluded that the method of assessing the strength increase required to counter the additional effect of P-delta in single degree of freedom structures can be successfully applied to multi-storey structures. A set of design steps for calculating the strength increase necessary to counter P-delta effects in structures is outlined. The distribution of strength increase within the structure is determined by a pinned jointed truss model with a deflected profile derived from either the equivalent static or modal response spectrum method. These strengths are then scaled by the appropriate single degree of freedom $\beta$ factor, modified by $K_{1}$ which allows for period and site condition, to obtain the total design actions.

\section{Notation}

$\alpha \quad$ Amplification factor,

B P-delta amplification factor,

$\delta \quad$ Horizontal displacement of a mass centroid,

$\delta_{\max } \quad$ Maximum displacement calculated for a given ductility demand neglecting P-delta actions,

$\delta_{\mathrm{i}} \quad$ Lateral deflection of the centre of the seismic mass at level i of a multi-storey structure,

$\Theta \quad$ Stability coefficient,

$\mu \quad$ Structural ductility factor,

$\mathrm{F}_{\mathrm{i}} \quad$ Lateral forces which are applied to a pin jointed truss model to balance the shear forces due to Pdelta actions,

$\mathrm{K}_{\mathrm{o}} \quad$ Lateral stiffness of a single degree of freedom model,

$\mathrm{K}_{\mathfrak{l}} \quad$ Factor which modifies $\mathrm{B}$ to allow for the influence of subsoil conditions,

M Base bending moment acting on the flexural spring of a single degree of freedom model,

$\mathbf{M}^{\prime} \quad$ Enhanced flexural strength required to maintain the same ductility when P-delta effect are included, $\left(\mathbf{M}^{\prime}=\alpha \mathbf{M}\right)$,

$P \quad$ Vertical load due to weight of mass,

$\mathrm{T}$ Fundamental elastic period of a structure,

$\mathrm{T}^{\prime} \quad$ Modified fundamental elastic period of a structure which includes the effects of P-delta,

V Horizontal force due to seismic actions on a mass, acting at the mass level. 


\section{References}

1. Standards Association of New Zealand 1991, "Code of Practice for General Structural Design and Design Loadings for Buildings", DZ 4203, 1991.

2. Applied Technology Council, "Tentative Provisions for the Development of Seismic Regulations for Buildings", ATC 3-06, National Bureau of Standards, Washington D.C., 1984 , pp. 58-59.

3. Bernal, D., "Amplification Factors for Inelastic Dynamic p- $\Delta$ Effects in Earthquake Analysis", Earthquake Engineering and Structural Dynamics, Vol. 15, 1987, pp. 635-651.

4. Panchia, N.M.B., "Influence of P-delta Effects on an Inelastic Single Degree of Freedom System", Master of Engineering Report, Department of Civil Engineering, University of Auckland, 1989.

5. Chung, B.T., "Dynamic Behaviour of Multi-Storey Buildings", School of Engineering Research Report No. 492, University of Auckland, 1991.

6. Fenwick, R.C. and Davidson, B.J., "Dynamic Behaviour of Multi-Storey Buildings", School of Engineering Research Report No. 463, University of Auckland, 1989.

7. Fenwick, R.C. and Davidson, B.J., "The Seismic Response of Multi-Storey Buildings", School of Engineering Research Report No. 495, University of Auckland, 1991, Chapter 4.

8. Fenwick, R.C. and Davidson, B.J., "Moment Redistribution in Seismic Concrete Resistant Frames", Proceedings of the Pacific Conference on Earthquake Engineering, Wairakei, NZ, Vol. 1, 1987, pp. 95-106.
9. Allahabadi, R. and Powell, G.H., "DRAIN-2DX User Guide", Earthquake Engineering Research Centre, University of California, Berkeley, Report No. EERC 88-06, 1988.

10. Standards Association of New Zealand, "Code of Practice for the Design of Concrete Structures", NZS 3101, Parts 1 and 2, 1982.

11. Mahin, S. and Boroschek, R., "Influence of Geometric Nonlinearities on the Seismic Response and Design of Bridge Structures", Background Report to California Department of Transportation Division of Structures, October, 1991.

12. Andrews, A.L., "Slenderness Effects in Earthquake Resisting Frames", Bulletin of the NZ National Society for Earthquake Engineering, Vol. 10, 1977, pp. 154158.

13. Paulay, T., "A Consideration of P-delta Effects in Ductile Reinforced Concrete Frames", Bulletin of the NZ National Society for Earthquake Engineering, Vol. 11, 1978, pp. 151-160.

14. Oughourlian, C.V. and Powell, G.H., "ANSR-III : General Purpose Computer Program for Nonlinear Structural Analysis", Earthquake Engineering Research Centre, University of California, Berkeley, Report No. EERC 82-21, 1982.

15. Thomson, E.D., Carr, A.J. and Moss, P.J., "P-delta effects in the Seismic Response of Ductile Reinforced Concrete Frames", Proceedings of the Pacific Conference on Earthquake Engineering, Auckland, NZ, Vol. 1, 1991, pp. 49-60. 